Multidisciplinary

SCIENTIFIC JOURNAL OF

MARITIME RESEARCH

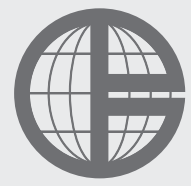

University of Rijeka

Faculty of Maritime

Studies Rijeka
Multidisciplinarni

znanstveni časopis

POMORSTVO

\title{
The analysis of the maintenance systems of a LPG carrier's liquefaction system main components
}

\author{
Aleksandar Vorkapić, Predrag Kralj, Dragan Martinović \\ University of Rijeka, Faculty of Maritime Studies Rijeka, Studentska 2,51000 Rijeka, Croatia, pkralj@pfri.hr
}

\begin{abstract}
The introductory part of this paper offers an overview of approaches on general marine maintenance and clarifies the significance of modern maintenance techniques, as well as their application in shipping practice. Unplanned down times and accidents, which result from inappropriate maintenance, create additional expenses. In today's shipping practice the widely shared concept of planned maintenance is not the most effective of the approaches. The appropriate maintenance system needs to prevent or reduce down times. Modern condition-based and reliability-centered maintenance systems recognize the market demand for a better ratio of the invested funds and complex tasks that the maintenance systems need to fulfill. The paper further analyses the possibilities of adjusting the maintenance intervals, which are shown on the example of a modern system for cargo liquefaction on a liquefied petroleum gas tanker.
\end{abstract}

\section{ARTICLE INFO}

\section{Review article}

Received 2 November 2016

Accepted 23 May 2017

\section{Key words:}

Preventive maintenance

Planned maintenance

Condition-based maintenance

Reliability-centered maintenance

Life cycle management

Life cycle expenses

Compressor

Liquefied petroleum gas tankers

\section{Introduction}

The traditional maintenance systems of marine systems are corrective (Corrective Maintenance - $\mathrm{CM}$ ) and preventive (Preventive Maintenance - PM). Corrective maintenance involves repairing the failures. Preventive systems are based on manufacturer's recommendations, where the interval is determined by the period of actual use (operating hours) or the overall period of time, regardless of the number of operating hours [1].

Preventive maintenance involves activities that include previously planned maintenance procedures during a specific amount of time in order to prevent the occurrence of failure and down times of a ship's technical system, as well as the increase of exploitation expenses [2].

The research has shown that machinery maintenance, in accordance with the number of operating hours, i.e. with the manufacturers' recommendation, is not the most effective one. The amount of money spent is not in proportion with the increased reliability. The ratio between the maintenance intensity and expenses is shown on a diagram on Figure 1. Cost optimization can be achieved by

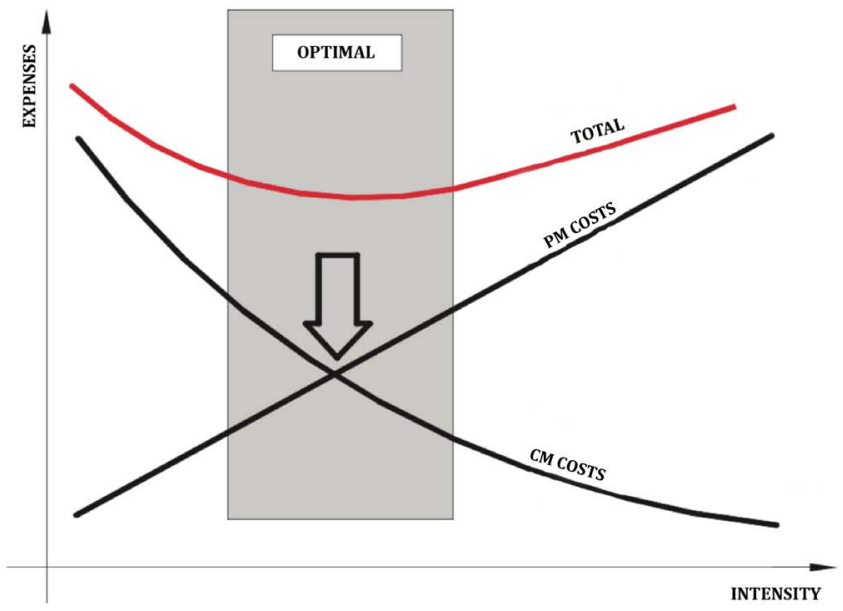

Figure 1 Maintenance Expenses Review [1] 


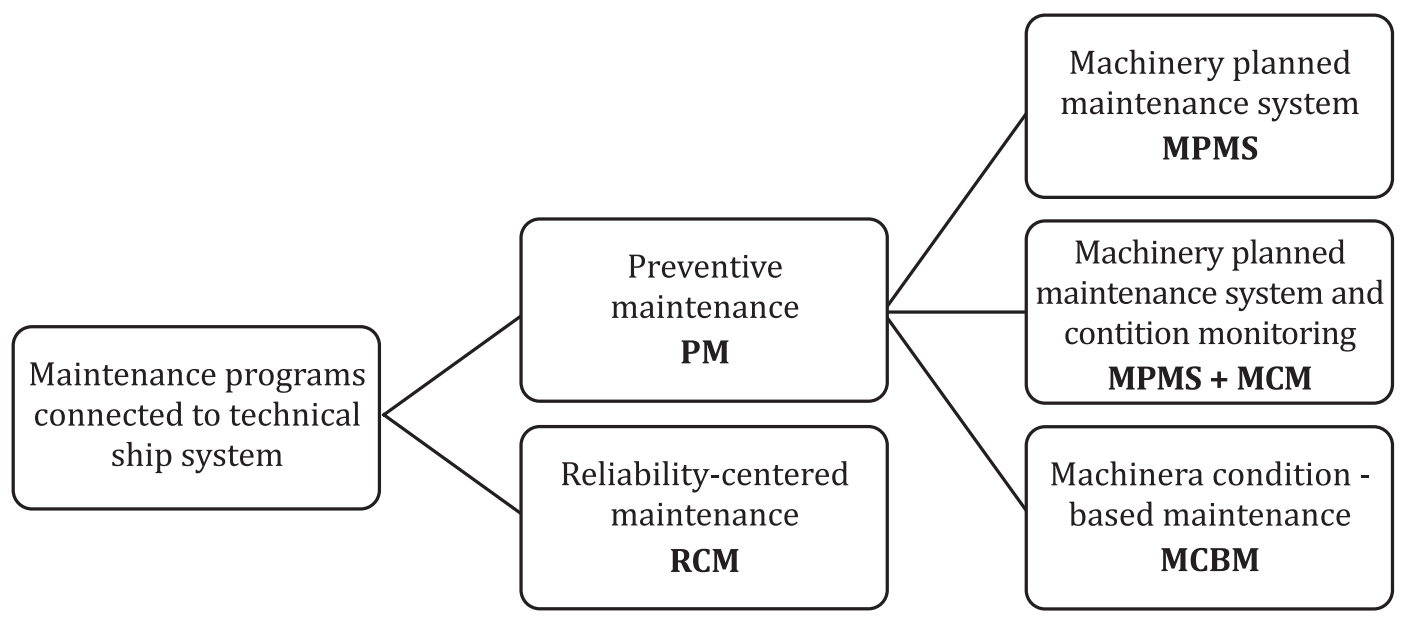

Figure 2 Ship's Technical System Maintenance Programmes [4]

moving the level of prevention to the left, i.e. by reducing the preventive maintenance expenses, as well as the PM/ CM ratio $[1,3]$.

In addition to the planned maintenance and in accordance with the manufacturers' recommendation, modern maintenance systems recognized by the classification societies are Machinery Condition Based Maintenance (MCB $\mathrm{M}^{1}$ ) and Reliability Centered Maintenance (RCM). Those systems are based on a detailed knowledge about the condition of the machinery, its failures and risks. Their intention is to maintain the reliability, availability and the efficiency rate with the lowest possible costs.

The reliability-centered maintenance programme is new in relation to others and it represents a synergy of various approaches with the goal of finding a cost-effective maintenance plan in accordance with the shipping company's needs.

Preventive maintenance can be machinery planned (MPMS), machinery planned with condition monitoring (MPMS+MCM) and condition-based maintenance (MCBM).

Preventive machinery condition-based maintenance is a philosophy of maintenance management which puts the decision on repair or replacement in relation to the condition of the asset. The main goal of preventive condition-based maintenance is to maintain the required functionality by reducing the overall expenses of inspection and repair. That can be achieved by continuous gathering of information on the system's condition, which is then processed in order to assess the situation and determine the necessity of maintenance [5].

Adjusting the maintenance interval of the system's components involves using the machinery conditionbased maintenance (MCBM) or the reliability-centered maintenance programme (RCM). Classification societies

1 Lloyd's Register's terminology and abbreviations are used in the paper. recognize RCM approach under certain conditions, main of which is an approved basic planned maintenance system (PMS) a ship must have.

\section{System maintenance programe for petroleum gas liquefaction according to the classification society}

The innovative system of petroleum gas, ammonia and petrochemical gases liquefaction, shown on Figure 3, has been developed by Babcock LGE Process and built in the Hyundai Heavy Industries (HHI) shipbuilding company in South Korea. Its goal is to achieve a better utilization and operability with a decreased initial investment, as well as operating costs. The initial investment is decreased by installing three compressors (instead of the usual four), while the higher cooling capacity is achieved by adding a Vent Gas Cooler (VGC) between the second and the third degree of compression.

The depicted reliquefaction system provides the following functions:

1. condensation of vapour produced by heat ingress to cargo whilst at sea and in port (thereby maintaining the tank pressure at the desired level),

2. condensation of vapour produced due to loading cargo where the vapour return to shore is not permitted,

3. reduction of the cargo temperature, in accordance with the charterer's requirements,

4. cool down warm cargo tank prior to loading a refrigerated cargo.

The vapour is drawn by the cargo compressor via the suction separator and compressed to the interstage condition in the economizer. The basic concept of the economizer is to improve the plant efficiency by reducing the temperature of the condensate returned to the tank. A portion of the condensate is flashed across a level con- 


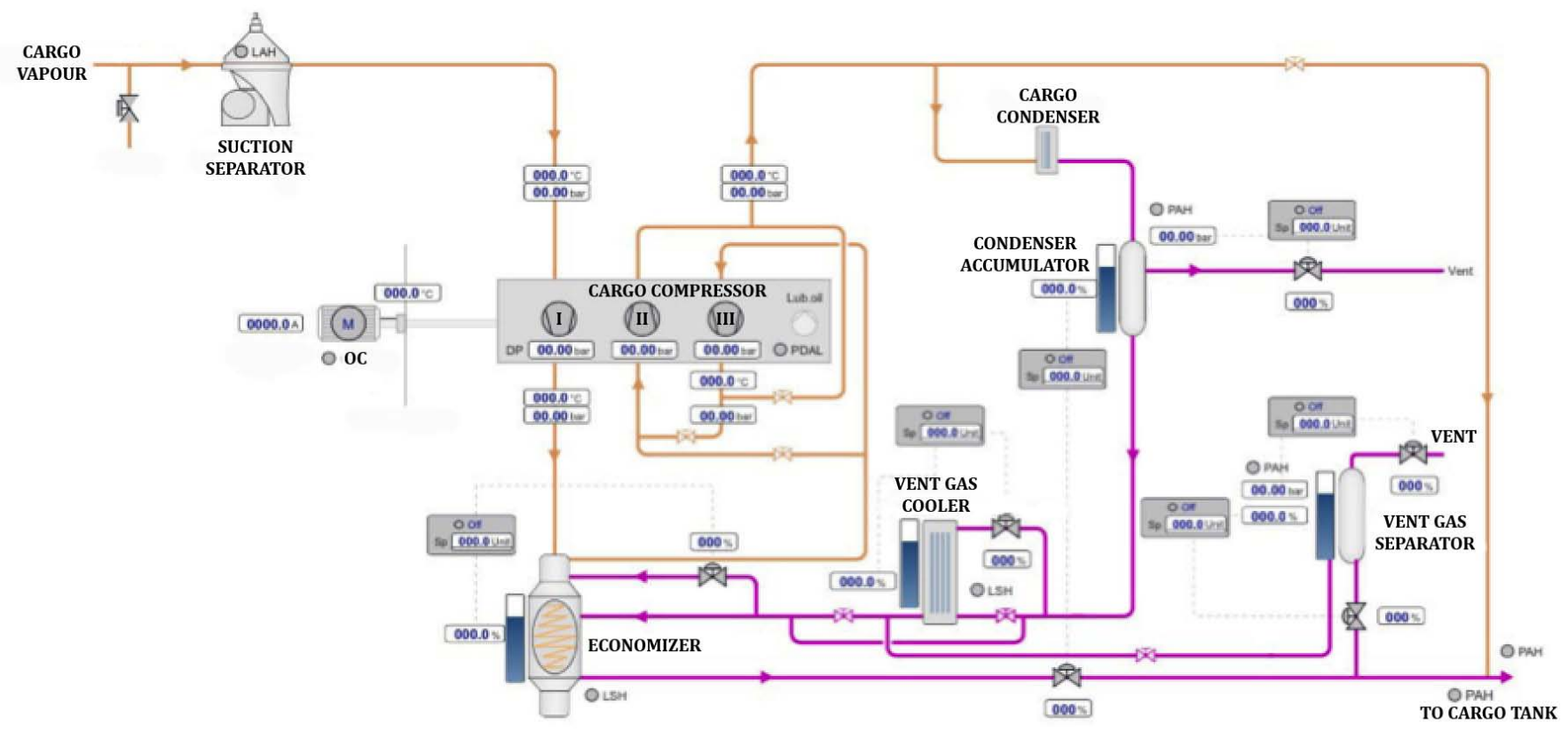

Figure 3 Petroleum Gas Reliquefaction System (a display of one compressor and the belonging elements of the system) [6]

trol valve and sprayed into the shell of the economizer. Gas passes from the economizer to the second stage suction and then (optionally) to the third stage of compression. Hot pressurized gas then passes through the shell side of the cargo condenser where it is cooled first to vapour and then to the liquid point by the seawater passing through the tubes of the condenser. The condensed liquid is then returned to the cargo tank. The vent gas cooler is installed to reduce the content of gases condensable only at lower temperatures. A large amount of non- condensable gases in the liquefied gas increases the pressure in the process thus reducing the liquefaction process efficiency. They are finally removed at the vent gas separator [6].

The system has installed components with a longer period of time between overhaul (TBO), which additionally reduces the operating costs. The first ship was delivered in 2014.

The ships that are part of the continuous survey machinery (CMS) programme can, by equalization of duty and introducing characteristic class codes for systems and for each of the components, enter the approved machinery planned maintenance scheme (MPMS) [4].

The machinery maintenance programme, approved by the classification society, enables the chief engineers to conduct an independent testing of the chosen machinery devices during a stated cycle, for the purpose of a continuous machinery inspection.

During a yearly inspection, a classification society's inspector reviews the approved electronic maintenance system, as opposed to single devices in a classical system of continuous inspection.

Table 1 List of Components of the Cargo Liquefaction system with a Maintenance Programme in accordance with MPMS [4]

\begin{tabular}{|l|l|c|}
\hline \multicolumn{1}{|c|}{ System } & \multicolumn{1}{|c|}{ Component } & \multicolumn{1}{c|}{$\begin{array}{c}\text { Reviewed by: } \\
\text { C/E: Chief engineer } \\
\text { CS: Classification society }\end{array}$} \\
\hline $\begin{array}{l}\text { Cargo cooling } \\
\text { system }\end{array}$ & Cargo compressor & \multicolumn{1}{c|}{ C/E } \\
\hline \multirow{2}{*}{$\begin{array}{l}\text { Circulator pumps } \\
\text { machinery }\end{array}$} & Independently powered pumps (and belonging electric motors with cables) & C/E \\
\hline & Pump-pipeline system \\
Submarine pipeline system & CS \\
& Main and supporting condensers/condensate return coolers & C/E \\
\hline
\end{tabular}


Table 2 Manufacturer's Recommended Maintenance Schedule [6]

\begin{tabular}{|c|c|c|c|c|c|c|c|}
\hline \multirow{2}{*}{ Type of maintenance } & \multicolumn{7}{|c|}{ Operating hours } \\
\hline & 4,000 & 8,000 & 16,000 & 24,000 & 32,000 & 40,000 & 48,000 \\
\hline Check adjustment and functionality of safety devices & $\mathrm{x}$ & $\mathrm{x}$ & $\mathrm{x}$ & $\mathrm{x}$ & $\mathrm{x}$ & $\mathrm{x}$ & $\mathrm{X}$ \\
\hline $\begin{array}{l}\text { Pipeline: } \\
\text { Check impermeability of screw connections, flanges and clamping } \\
\text { elements }\end{array}$ & $\mathrm{x}$ & $\mathrm{x}$ & & $\mathrm{x}$ & & $\mathrm{x}$ & \\
\hline $\begin{array}{l}\text { Automatic condensate drains: } \\
\text { Valves, valve seats, valve plate, nozzle, position switch }\end{array}$ & $\mathrm{x}$ & $\mathrm{x}$ & $\mathrm{x}$ & $\mathrm{x}$ & $\mathrm{x}$ & $\mathrm{x}$ & $\mathrm{X}$ \\
\hline $\begin{array}{l}\text { Damper: } \\
\text { Check damper condition }\end{array}$ & & $\mathrm{x}$ & $\mathrm{x}$ & $\mathrm{x}$ & $\mathrm{x}$ & $\mathrm{x}$ & $\mathrm{X}$ \\
\hline $\begin{array}{l}\text { Relief valves: } \\
\text { Check relief valves opening }\end{array}$ & & $\mathrm{x}$ & & $\mathrm{x}$ & & $\mathrm{x}$ & \\
\hline $\begin{array}{l}\text { Check valves of process gas: } \\
\text { Check opening and condition of relief valves }\end{array}$ & & $\mathrm{x}$ & & $\mathrm{x}$ & & $\mathrm{x}$ & \\
\hline $\begin{array}{l}\text { Drain oil, clean oil filters (duplex and crosshead bearing) } \\
\text { First time after } 200 \text { operating hours }\end{array}$ & & $\mathrm{x}$ & $\mathrm{x}$ & $\mathrm{x}$ & $\mathrm{x}$ & $\mathrm{x}$ & $\mathrm{X}$ \\
\hline Check suction and supply valves & & $\mathrm{x}$ & $\mathrm{x}$ & $\mathrm{x}$ & $\mathrm{x}$ & $\mathrm{x}$ & $\mathrm{X}$ \\
\hline Check clearance between a piston rod and a guide bearing & & $\mathrm{x}$ & $\mathrm{x}$ & $\mathrm{x}$ & $\mathrm{x}$ & $\mathrm{x}$ & $\mathrm{X}$ \\
\hline Check sealing rings and replace them if necessary & \multicolumn{7}{|c|}{ In case of gas leakage } \\
\hline $\begin{array}{l}\text { Check piston crown tightness (for pistons larger than } 480 \mathrm{~mm} \text { in } \\
\text { diameter) }\end{array}$ & & & $\mathrm{x}$ & & $\mathrm{x}$ & & $\mathrm{x}$ \\
\hline Check if the flexible coupling is centered & & & $\mathrm{x}$ & & $\mathrm{x}$ & & $\mathrm{X}$ \\
\hline $\begin{array}{l}\text { Remove a few main bearings, connecting rods and large end } \\
\text { bearings for spot check }\end{array}$ & & & & $\mathrm{x}$ & & & $\mathrm{X}$ \\
\hline Clean cooling spaces, gas and oil coolers, check belonging seals & \multicolumn{7}{|c|}{ Depending on pollution and chemical treatment of the cooling liquid } \\
\hline Check shaft seal (replace if necessary) & \multicolumn{7}{|c|}{ In case of leakage } \\
\hline Check insulation resistance of electric compressor motor & $\mathrm{x}$ & $\mathrm{x}$ & $\mathrm{x}$ & $\mathrm{x}$ & $\mathrm{x}$ & $\mathrm{x}$ & $\mathrm{x}$ \\
\hline $\begin{array}{l}\text { Check electric compressor motor vibrations } \\
\text { (for horizontal motors) }\end{array}$ & \multicolumn{7}{|c|}{ Every 6 months or, if necessary, in case of vibrations } \\
\hline
\end{tabular}

\section{Adjusting maintenance intervals}

The single component or system ability to perform its task or function is changing with the time or with the running hours. Time to failure or mean time between failures governs the frequency of the component or system inspection or maintenance interval (Figure 4).

Manufacturers have recommended intervals that, as well as the demands of the Classification Society, can be adjusted in terms of condition-based maintenance and reliability-centered maintenance programmes. The most important factor in both strategies is the evaluation of the existing condition by means of regular inspection. The gathered information should then be stored on standard forms for further analysis and use and for the crew to become familiar with the wear and tear. The intervals between inspections should be shorter initially and increased gradually with the verification of a wear rate. 


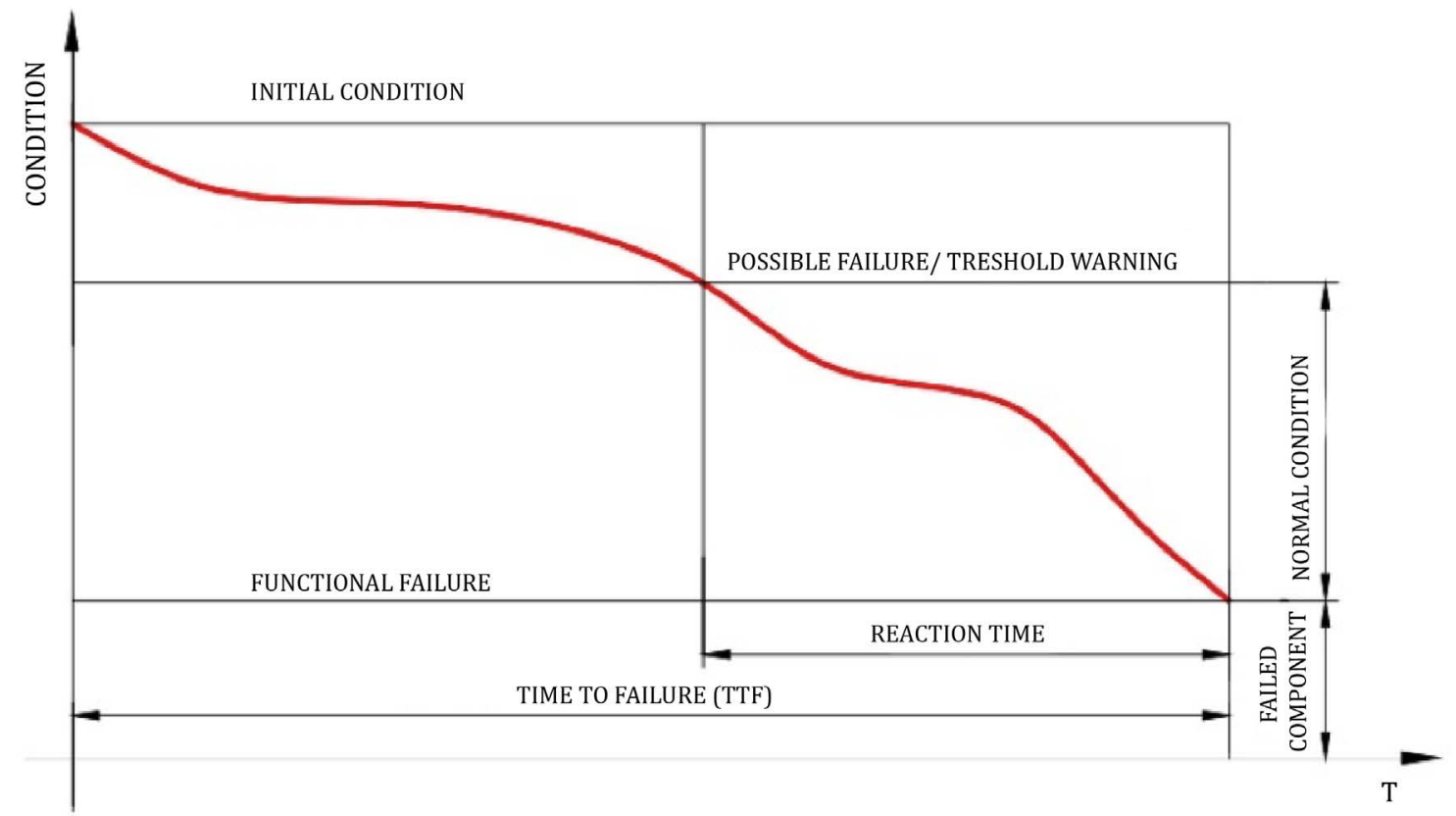

Figure 4 Component Condition/Time to Failure Diagram

Condition-based maintenance is effective when a potential failure can be detected by means of operating monitoring parameters (some of which are described below), by equipment that will reveal the impairment or through inspection.

In a specific case, the condition monitoring can be carried out using the following methods:

- The state of the compressor can be precisely determined by a laboratory analysis of the oil, during which the lubricant data, concentration of wear elements, contaminant elements and additive elements are determined.

- Modern bearing condition monitoring devices include several functions, such as continuous monitoring of the wear of the bearings, measuring the temperature of bearings, the percentage of water in the oil, and, quite often, monitoring the temperature of the cylinder and the shaft torque. The system monitors the wear of main bearings, crosshead bearings and large end bearings. Its objective is to give an early warning in case of excessive wear of bearing bush material, in order to prevent the damaging of the crankshaft and the connecting rod. The sensor works in a way that it emits eddy current, and it is used to measure conductive, ferromagnetic material. The changes in the material result in the change of the measured feedback signal.

- Vibration control, along with oil analysis, represents the most frequently used method in monitoring the device condition. The changes of the condition of the device affect the vibration changes. The system of vibration and condition monitoring is based upon a pre- viously defined concept. It is important to note that, regardless of the monitoring system, the programme demands need to be precisely defined based on the machinery type (that is being monitored), the failure type and the machinery faults [1].

A significant amount of data is gathered every day through the existing automatic monitoring systems or manually, and it is used for managing and recording the condition of the machinery. In a specific case, the alarm and machinery monitoring system K-Chief 600 gathers operating parameters that are available for further use. A part of those data can be successfully utilized for condition monitoring and the creation of a database without additional expenses. As an example of is the failure of the compressor supply valves, which can be detected by reducing the difference between the inlet and supply pressure under given conditions.

More complex maintenance models, besides analysing the condition of a device, involve an analysis of previous failures, their frequency, and the categorization of failures and devices by relevance. Various methods are used for risk analysis and the analysis of the failure probability. One of them is the already mentioned reliability-centered maintenance programme.

Classification Societies recognize the RCM approach under certain conditions, the main of which is an approved basic planned maintenance system (PMS) a ship must have.

RCM is defined as: "a process which determines what needs to be done in order to ensure that physical assets continue to do what is expected of them in given operating conditions." [4] 
RCM entails asking seven basic questions about the asset or system, in order to find the tools to ensure that the technical system will achieve a maximum efficiency:

1. What are the functions and associated performance standards of the asset in its present operating context? This entails not only basic, but also additional functions, and it clearly defines the expectations and performance standards necessary for the device to operate in a satisfactory manner.

2. In what ways does the asset fail to fulfill its function? This includes defining the circumstances that led to the failure.

3. What causes each functional failure? The event which is likely to cause each failed state (failure mode) is recognized here.

4. What happens when each failure occurs? The consequences of the failure are explained here, depending on the event that caused it.

5. In what way does each failure matter? The consequences of failure are recognized and categorized into those connected to the safety of lives, environmental protection, operating or non-operating consequences, and hidden consequences (e.g. a protection device that is not made in a 'fail-safe' mode). A failure mode and effects analysis (FMEA) is conducted.

6. What can be done to predict or prevent each failure? The procedure has to be set before the occurrence of failure. These preventive procedures help with predictive and preventive maintenance techniques.

7. What should be done if a suitable proactive task cannot be found? Actions that result in failure, and for which there is not an efficient preventive procedure, are recognized. The device is then either redesigned or used differently in order to prevent the failure.

The goal of this machinery maintenance programme is to select the most effective maintenance procedure and inspection intervals for all types of failures that have been categorized as critical ones by the cause and effect analysis. A corrective maintenance approach is chosen for noncritical failures.

RCM is a systematic strategy with clear objectives. It requires a high level of expertise of several people who have participated in its designing and it is simple to use in everyday situations. However, since it is focused on detecting and analysing as many potential failures as possible, the process requires a comprehensive failure mode and effects analysis, which can be time-consuming.

Figure 5 shows a contemporary maintenance model and the adjustment of operating hours. The model includes several steps for processing data on the history of the failure and maintenance, which are then disaggregated and sent from the ship to the office. The gathered data are analysed in the office, after which the probability of failure is determined by using the Weibull distribution, thus setting a new interval. The interval is compared to the manufacturer's recommendations and a new standard is set [7].

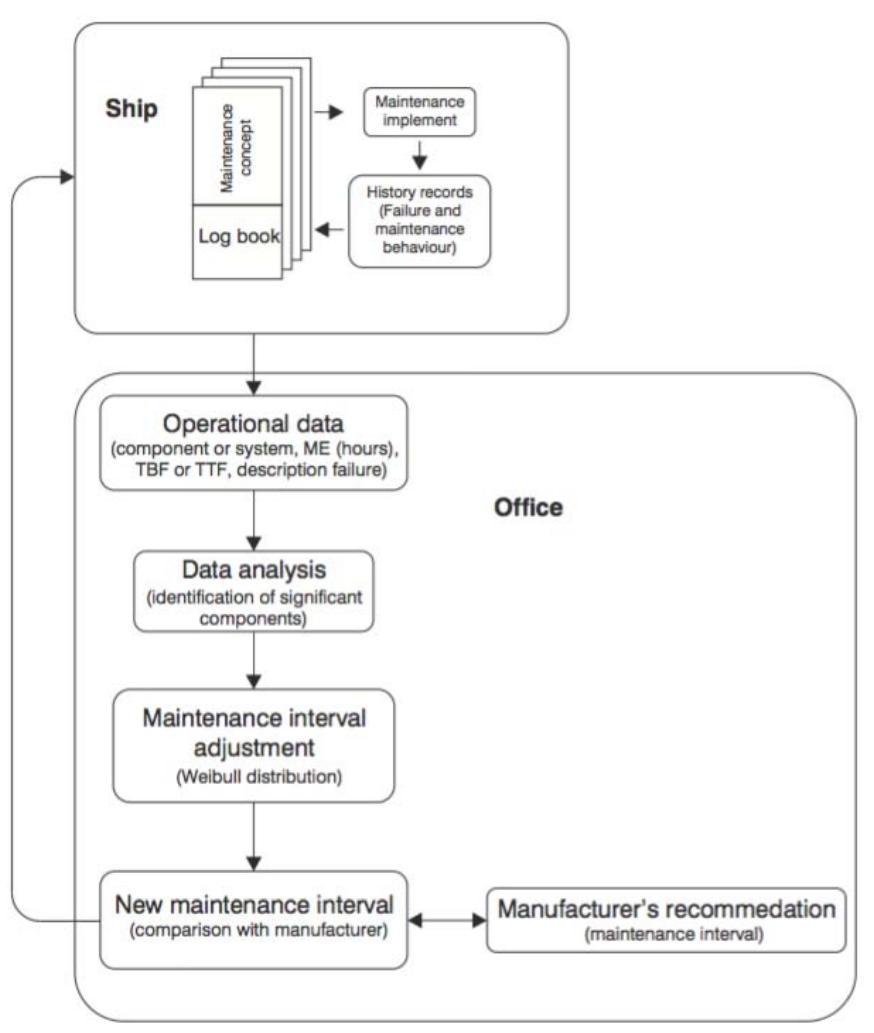

Figure 5 Interval Adjustment

That model is not flawless because it can only be corroborated when there is sufficient information. The shipping companies with newly built or few ships may find it ineffective. For instance, a sufficient database does not exist when it comes to new devices, such as cargo compressor, that should serve as the base for making quality decisions on the intervals. The manufacturer has set the interval high at the very beginning and can, therefore, be further adjusted only by a quality analysis of the operating parameters.

The Kongsberg firm has developed an electronic logbook with a unique database, in which the automatically or manually gathered data are stored. The application is completely integrated into the existing architecture of the monitoring, alarm and management system, while the archived data are easily accessible and can be used for various purposes. Any data gathered by an external information gathering system can be added as well, and continuously stored, if necessary. That kind of infrastructure can be connected to the maintenance programme, which enables the detection of a functional failure by means of condition monitoring before an actual component failure occurs.

Maintenance concept adjustment and design (MACAD) [3] is based on the gathered data on failures and maintenance as well. Interval adjustment depends on operating data. Similarly to the previous method, the MA-CAD method starts with dividing the system into subsystems and components, it continues with the risk and failure mode analysis, and it involves a maintenance con- 
cept. However, there is also an issue with new propulsion and smaller shipping companies, where the gathered data are not sufficient for a quality analysis.

In the specific liquefaction system, where the interval is set high, a combination of planned maintenance with condition monitoring or a preventive condition-based maintenance programme would bring about the optimal ratio between cost and reliability.

\section{Conclusion}

The paper provides an overview of current maintenance programmes and approaches to interval adjustment of significant LPG carrier liquefaction plant components. Despite the fact that there are advanced systems available, the shipping companies still opt for a conservative form of preventive operating hours or calendar-based maintenance.

Those types of systems are complex and require continuous monitoring. The systems are not available on the market as a final product. They need to be developed through a certain period of time. Partial culprits are the original equipment makers (OEM), which usually do not have the quality supporting documents that would help in creating more advanced programmes. That makes room for those who are directed towards the future and who could thus take over the market from those who do not adjust in time.

Classification Societies play a leading role in recognizing modified programmes and modern trends, which are offered as an option when choosing a programme.

A complete integration of an alarm and monitoring system (AMS) and a maintenance system, where the gathered data would be analysed by using one of the mentioned methods in an electronic maintenance system, would certainly be a positive step forward.

\section{References}

[1] I. Šegulja, A. Bukša, Održavanje brodskog pogona, Pomorstvo, Rijeka, Godina 20, 2 (2006), pp. 105-118.

[2] I. Šegulja, A. Bukša, V. Tomas, Održavanje brodskih sustava, Rijeka, Pomorski Fakultet Sveučilišta, 2009.

[3] B. Vučinić, MA - CAD, Maintenance Concept Adjustment and Design, Delft, Faculty of Mechanical Engineering and Marine Technology, 1994.

[4] Lloyds Register, Machinery Planned Maintenance and Condition Monitoring, 2013.

[5] B. A. Ellis, Condition based maintenance, 2008.

[6] Babcock, LGE Process Manual, 13033-PM-13-015-01.

[7] I. Šegulja, A. Bukša, V. Tomas, Maintenance Interval Adjustment of Significant Ship Propulsion Components, University of Rijeka, Faculty of Maritime Studies, 2009. 